\title{
The Relationship between Intravascular Volume Expansion and Natriuresis in Developing Puppies
}

\author{
MORDECHAI ALADJEM, ADRIAN SPITZER, AND DAVID I. GOLDSMITH ${ }^{(34)}$
}

Department of Pediatrics, Division of Nephrology, Albert Einstein College of Medicine, Bronx, New York, USA

\begin{abstract}
Summary
The role played by the relative degree of expansion of the intravascular and extravascular compartments in limiting the natriuretic response of fluid-loaded developing animals was determined in 1-, 2-, 3- and 6-wk-old puppies. Volume expansion was induced by infusing either isotonic saline, $10 \%$ body weight or isoncotic albumin in saline $5 \%$ body weight, and measurements of glomerular filtration rate, sodium excretion, fractional excretion of sodium, and plasma volume were made. Each expansion procedure resulted in an increase in the absolute excretion of sodium at all ages $(P<0.001)$. The greatest natriuretic effect was observed in the 3-wk-old puppies, the average of the two solutions being 19, 30,70 , and $28 \mu \mathrm{Eq} / \mathrm{min} / \mathrm{kg}$ in the $1,2,3$, and 6-wk-old animals, respectively. The difference in natriuresis among the age groups was due predominantly to differences in the magnitude of the increase in fractional excretion of sodium. At all ages, a greater absolute excretion of sodium was encountered during volume expansion with saline than observed with albumin $(P<0.05)$. The intravascular volume increased by a similar $\%$ at all ages $(P>$ 0.1 ), and saline and albumin yielded equivalent degrees of intravascular expansion (approximately $50 \%$ ). The results demonstrate that age-related changes in natriuretic response to volume expansion cannot be attributed to differences in either the degree of expansion or the distribution of the load. In addition, the observations indicate that the mechanism underlying the difference between the response to isotonic saline and isoncotic albumin in saline is already operative at birth, and that it is independent of nephron heterogeneity since the proportion of superficial nephrons must have changed during the period of nephrogenesis.
\end{abstract}

\section{Speculation}

The collecting duct, which is sensitive to both isotonic saline and isoncotic albumin, is likely to be responsible for the parallel development of the renal response to these two methods of intravascular volume expansion.

It has been amply demonstrated that the excretory response to saline expansion is less in neonatal and developing animals than it is in mature subjects $(1,7,12,13,16)$. Early investigators have suggested that the low glomerular filtration rate (GFR), which prevails during this period of development, limits the natriuresis elicited by volume expansion. This concept has been recently challenged. Our work (7) and that performed by others $(12,13)$ have demonstrated that an avid reabsorption by the renal tubule rather than a low GFR is the main cause of the limited natriuresis observed in infancy. The mechanism responsible for the persistence of a high fractional reabsorption in developing animals, even under conditions of volume expansion, has not as yet been established. We reasoned that "immaturity" of the transport mechanism could not provide an adequate explanation for this phenomenon because reabsorption of sodium is a process that requires the expenditure of energy, and as such it might be expected to be less efficient in the developing than in the developed animals. It therefore seemed reasonable to consider that the stimulus to limit sodium reabsorption may be of lesser magnitude in the newborn than in the mature animal. Both the distribution $(5,10,14)$ and the extent $(30,31)$ of a volume load are known to influence the magnitude of the diuretic response. Because both total body water and especially the extracellular fluid compartment are known to decrease with age relative to body weight $(3,4,9)$, it seemed conceivable that the degree of expansion of these compartments may increase when a load of saline is calculated on the basis of body weight. In addition to the changes in total body water and extracellular fluid volumes, the ratio of plasma volume:extracellular volume increases as a function of age $(3,4,9,17,22)$. Thus, if the load is distributed in proportion to the relative sizes of the extracellular fluid compartments, a lesser expansion of either the intravascular or interstitial fluid in the newborn, as compared to the adult, might account for the limited natriuresis in developing subjects. On the other hand, an infusion of isoncotic albumin is expected to have a minimal impact on the interstitial fluid compartment and its effect therefore should reflect predominantly the changes in the intravascular space.

\section{MATERIALS AND METHODS}

Mongrel puppies of either sex born in our animal quarters were studied at one of four ages corresponding to distinct stages of renal maturation (2): 4-7, 11-14, 20-24, or 44-47 days. One day before the study, the animals were anesthetized with ether, catheters were placed in the femoral artery and vein, sealed and tunneled subcutaneously to the nape of the neck. Another catheter was placed into the bladder via an incision into the urethra, close to its junction with the bladder. The animals were allowed to awaken and were returned to the mother for a 24-h recovery period.

On the day of the study, $2 \mathrm{ml}$ of blood were taken and the red cells tagged with $\left[{ }^{51} \mathrm{Cr}\right]$ according to the procedure described in a commercially manufactured kit (Chromotope, Squibb). Half of the tagged cells were reinjected into the animal, and the remainder of the sample served for determination of the specific activity. After a bolus injection of inulin $(0.5 \mathrm{ml} / \mathrm{kg}$ body weight $)$ in a $10 \%$ solution, an infusion of $1 / 3$ isotonic saline in $5 \%$ dextrose was given at a rate of $5 \mathrm{ml} / \mathrm{kg}$ body weight per $\mathrm{h}$. This solution contained sufficient inulin to maintain a plasma concentration of approximately $25 \mathrm{mg} / \mathrm{dl}$. A 1-h equilibration period was allowed to elapse, and three urine collections, each of $15 \mathrm{~min}$ duration, were then obtained. Thereafter the plasma volume was expanded. Five animals in each age group were given infusions of isotonic saline solution. A volume of fluid corresponding to $10 \%$ body weight was administered over a 45-min period. A separate set of 6 animals in each age group were infused with isoncotic albumin in isotonic saline. The volume of the albumin solution, also given over a 45min period, was equivalent to $5 \%$ body weight. This regimen was chosen because our pilot studies indicated that it resulted in a degree of intravascular expansion similar to that provoked by a $10 \%$ body weight load of isotonic saline. Urine and blood were collected every $15 \mathrm{~min}$ during the loading procedure. Samples 
were also obtained at $15 \mathrm{~min}$ intervals for $45 \mathrm{~min}$ following the completion of volume expansion. The bladder was flushed with 1-2 cc room air at the end of each period in order to assure complete urine collections. No attempt was made to replace urinary losses of fluid.

Inulin was added to the expansion fluids in order to minimize possible changes in the plasma inulin concentration consequent to dilution or the anticipated increase in GFR (7). After each blood collection, the red cells were separated from the plasma, and were reinfused in a volume of saline equal to that of the plasma removed. One $\mathrm{ml}$ samples of blood were obtained immediately before and after volume expansion as well as $45 \mathrm{~min}$ after completing the expansion procedure for determination of intravascular volume and hematocrit. All blood samples were withdrawn via the arterial catheter whereas infusions were given via the venous line. Blood pressure was measured and recorded throughout the experiment. At the conclusion of the study the animals were sacrificed, and the bladder was examined in order to verify the lack of residual urine. The kidneys were removed and weighed.

Alkali stable inulin concentration in blood and urine was determined by the method of Walser et al. (32). Sodium and potassium concentration were measured by flame photometry. Radioactivity of blood samples was counted in a well type Gamma scintillation counter (Intertechnique, SL-40).

GFR, the absolute excretion of sodium $\left(\mathrm{U}_{\mathrm{Na}} \mathrm{V}\right)$ and fractional excretion of sodium ( $\mathrm{FeNa}$ ) were calculated with standard formulae. Blood volume was calculated by using a sample dilution formula and this value was corrected for hematocrit in order to determine plasma volume (PV). No adjustments were made for differences in peripheral and central hematocrit.

The statistical significance of changes occurring during the course of the experiment was assessed with a paired $t$ test. Agerelated differences in response to the two modes of expansion were tested for significance by analysis of variance (23).

\section{RESULTS}

Effect of saline expansion. PV, corrected for differences in body weight, (Table 1), was similar $(P>0.5)$ in the four age groups before volume expansion. Immediately after the conclusion of volume expansion, the $\mathrm{PV} / \mathrm{kg}$ body weight was significantly larger $(P<0.01)$ than that observed in the control period in each of the age groups, but there were no significant differences among the groups. In the ensuing $45 \mathrm{~min}, \mathrm{PV}$ fell, remaining significantly above the control values $(P<0.05)$ only in the $1-$ and 2 -wk-old puppies. Significant differences between the age groups in either the ratios of, or the differences between, the pre- and postexpan-

Table 1. Plasma volume ( $\mathrm{ml} / \mathrm{kg}$ body weight) in developing puppies sustaining volume expansion (mean \pm S.E.)

\begin{tabular}{|c|c|c|c|}
\hline \multirow[b]{2}{*}{ Age (wks) } & \multicolumn{3}{|c|}{ Period } \\
\hline & Control & $\begin{array}{l}\text { Immediately } \\
\text { after expansion }\end{array}$ & $\begin{array}{c}45 \text { min after } \\
\text { expansion }\end{array}$ \\
\hline \multicolumn{4}{|l|}{ Saline } \\
\hline \multicolumn{4}{|l|}{$10 \%$ body weight } \\
\hline 1 & $58 \pm 3$ & $77 \pm 2$ & $68 \pm 2$ \\
\hline 2 & $62 \pm 4$ & $87 \pm 4$ & $70 \pm 4$ \\
\hline 3 & $61 \pm 6$ & $86 \pm 5$ & $64 \pm 6$ \\
\hline 6 & $65 \pm 6$ & $95 \pm 6$ & $75 \pm 4$ \\
\hline$P^{1}$ & $>0.8$ & $>0.1$ & $>0.4$ \\
\hline \multicolumn{4}{|l|}{ Albumin } \\
\hline \multicolumn{4}{|l|}{$5 \%$ body weight } \\
\hline 1 & $59 \pm 7$ & $79 \pm 6$ & $70 \pm 6$ \\
\hline 2 & $74 \pm 6$ & $104 \pm 9$ & $89 \pm 8$ \\
\hline 3 & $64 \pm 7$ & $89 \pm 9$ & $83 \pm 9$ \\
\hline 6 & $58 \pm 7$ & $79 \pm 7$ & $71 \pm 5$ \\
\hline$P$ & $>0.3$ & $>0.1$ & $>0.2$ \\
\hline
\end{tabular}

${ }^{1}$ Significance levels of differences between age groups. sion values were not demonstrable by analysis of variance $(P>$ 0.2 ).

Before volume expansion, $\mathrm{U}_{\mathrm{Na}} \mathrm{V} / \mathrm{kg}$ body weight was similar in the four age groups (Table 2). During the expansion procedure (periods $1-3), \mathrm{U}_{\mathrm{Na}} \mathrm{V}$ increased in each age group $(\mathrm{P}<0.05)$, and after expansion (periods 4-6), $U_{\mathrm{Na}} \mathrm{V}$ fell in the 1-, 2-, and 3-wkold puppies, whereas it tended to remain near the peak value in the 6-wk-old animals. At each age, $\mathrm{U}_{\mathrm{Na}} \mathrm{V}$ was higher at the conclusion of the experiment than it was during the control period. Age related differences in the natriuresis elicited by saline expansion were demonstrable both during and after expansion (periods $2-4$, Table 2). The largest natriuretic response was observed in the 3-wk-old animals.

The enhancement in sodium excretion observed during expansion was associated with significant $(P<0.05)$ increases in GFR (Table 3 ), in all age groups, and in the $\mathrm{FeNa}$ in all but the youngest group of animals (Table 4). After completion of the expansion procedure, the GFR returned towards control values whereas the $\mathrm{FeNa}$ remained elevated in all groups $(P<0.05)$.

The relative contribution of the changes in GFR and FeNa to the overall natriuretic response varied between age groups. Although the increases in GFR did not differ significantly among the four age groups, the rise in $\mathrm{FeNa}$ varied. The maximal increases in GFR after expansion with saline solution were $81 \pm$ $41,120 \pm 47,106 \pm 96$, and $53 \pm 42 \%$ of the control values in the 1-, 2-, 3- and 6-wk-old animals, respectively $(P>0.5)$. On the other hand, the maximal differences in $\mathrm{FeNa}$ between control and postexpansion was much higher in the 3-wk-old animals $(7.1 \pm$ $2.0 \%$ ) than that observed in the 1-, 2- and 6-wk-old puppies (1.9 $\pm 1.1,3.3 \pm 0.6$, and $2.6 \pm 0.9 \%)$, respectively $(P<0.05)$. Thus, the age-related differences in natriuresis were due, in large part, to differences in the tubular reabsorption of sodium.

Isoncotic albumin expansion. The results of the measurements of $\mathrm{PV} / \mathrm{kg}$ body weight in the puppies sustaining isoncotic volume expansion are shown in Table 1 . There were no significant differences among the age groups before volume expansion. Immediately after the expansion procedure PV was higher than during the control period in every animal $(P<0.01)$, but there was no significant difference in the ratio of or changes in the PV among the age groups $(P>0.2)$. During the ensuing $45 \mathrm{~min}, \mathrm{PV}$ fell but remained significantly higher than control in each of the age groups $(P<0.01)$.

The natriuretic responses consequent to expansion with isoncotic albumin were similar to those observed following saline administration. $\mathrm{U}_{\mathrm{Na}} \mathrm{V} / \mathrm{kg}$ body weight (Table 2 ) increased in each age group during expansion and remained significantly above control value $(P<0.05)$ for at least $45 \mathrm{~min}$ after its conclusion in the 2-, 3-, and 6-wk-old animals. In the 1-wk-old puppies the $\mathrm{U}_{\mathrm{Na}} \mathrm{V} / \mathrm{kg}$ was higher during the last $30 \mathrm{~min}$ of the study than during the control period but the difference was not statistically significant $(P>0.2)$. The mean $\mathrm{U}_{\mathrm{Na}} \mathrm{V}$ during and after expansion was highest in 3-wk-old puppies, with the exception of the last 15 min of the study when the 6-wk-old animals had the highest excretory rate.

The changes in GFR and FeNa observed during and after volume expansion induced with isoncotic albumin are summarized in Tables 3 and 4. GFR increased during expansion and returned towards base line values by the end of the study. In the 1-wk-old animals the increase was not statistically significant at any time $(P>0.1)$ whereas in the other three age groups significant increases were achieved towards the end of expansion $(P<0.05)$. Although the GFR increased with age (Table 3), the maximal increment in GFR consequent to volume expansion was proportional to the control value being $45.8 \pm 22.8,49.7 \pm 20.3,117.7$ \pm 53.8 , and $37.8 \pm 10.2 \%$ in the 1-, 2-, 3- and 6-wk-old puppies, respectively, $(P>0.3)$.

The changes in FeNa that occurred during the course of expansion with isoncotic albumin closely paralleled those observed following saline expansion. $\mathrm{FeNa}$ increased in each age group during expansion, significant differences between age groups being observed throughout most of the course of the experiment (Table 
Table 2. $U_{N a} V(\mu E q / m i n$ per $k g$ body weight) in puppies sustaining volume expansion (mean $\pm S . E$.

\begin{tabular}{|c|c|c|c|c|c|c|c|}
\hline Age (wk) & \multicolumn{7}{|c|}{ Period } \\
\hline \multicolumn{8}{|l|}{$\begin{array}{l}\text { Saline } \\
10 \% \text { body weight }\end{array}$} \\
\hline 1 & $2.1 \pm 0.7$ & $2.5 \pm 0.7$ & $8.6 \pm 7.0$ & $24.4 \pm 8.5$ & $11.4 \pm 5.2$ & $6.6 \pm 2.6$ & $6.3 \pm 2.7$ \\
\hline 2 & $4.6 \pm 2.3$ & $9.9 \pm 4.8$ & $26.8 \pm 11.9$ & $34.4 \pm 16.1$ & $31.0 \pm 8.3$ & $24.6 \pm 5.8$ & $18.3 \pm 5.7$ \\
\hline 3 & $6.0 \pm 2.5$ & $17.0 \pm 6.2$ & $58.6 \pm 21.4$ & $89.5 \pm 24.1$ & $66.2 \pm 6.2$ & $31.8 \pm 3.7$ & $25.5 \pm 8.9$ \\
\hline \multicolumn{8}{|l|}{ Albumin } \\
\hline \multicolumn{8}{|l|}{$50 \%$ body weight } \\
\hline 1 & $3.0 \pm 0.7$ & $1.6 \pm 0.8$ & $3.7 \pm 1.5$ & $24.5 \pm 8.6$ & $14.6 \pm 3.3$ & $9.7 \pm 3.5$ & $6.5 \pm 3.2$ \\
\hline 2 & $2.3 \pm 0.9$ & $2.3 \pm 1.1$ & $10.4 \pm 3.1$ & $27.4 \pm 8.7$ & $21.5 \pm 5.4$ & $18.1 \pm 5.6$ & $13.9 \pm 3.3$ \\
\hline 3 & $2.1 \pm 0.4$ & $5.8 \pm 2.3$ & $21.2 \pm 4.8$ & $55.1 \pm 9.7$ & $56.4 \pm 9.8$ & $57.7 \pm 11.5$ & $26.6 \pm 6.1$ \\
\hline 6 & $2.1 \pm 1.1$ & $2.9 \pm 1.1$ & $9.7 \pm 1.4$ & $27.1 \pm 4.7$ & $36.9 \pm 8.6$ & $33.2 \pm 4.4$ & $33.2 \pm 4.1$ \\
\hline
\end{tabular}

Table 3. Glomerular filtration rate ( $\mathrm{ml} / \mathrm{min} \mathrm{kg}$ body weight) in puppies sustaining volume expansion (mean $\pm S$.E.)

\begin{tabular}{|c|c|c|c|c|c|c|c|}
\hline Age (wks) & \multicolumn{7}{|c|}{ Period } \\
\hline \multicolumn{8}{|l|}{ Saline } \\
\hline 1 & $2.7 \pm 0.5$ & $3.4 \pm 0.5$ & $3.7 \pm 1.0$ & $5.0 \pm 1.5$ & $4.8 \pm 0.9$ & $2.1 \pm 0.5$ & $2.5 \pm 0.7$ \\
\hline 2 & $2.2 \pm 0.2$ & $4.1 \pm 0.9$ & $4.4 \pm 0.8$ & $4.3 \pm 0.9$ & $3.7 \pm 0.6$ & $3.6 \pm 0.5$ & $2.8 \pm 0.3$ \\
\hline 3 & $6.2 \pm 1.0$ & $10.0 \pm 2.4$ & $8.5 \pm 0.6$ & $11.1 \pm 4.2$ & $6.9 \pm 1.0$ & $6.2 \pm 1.3$ & $4.9 \pm 1.4$ \\
\hline \multicolumn{8}{|l|}{ Albumin } \\
\hline \multicolumn{8}{|l|}{$5 \%$ body weight } \\
\hline 1 & $4.2 \pm 0.4$ & $4.3 \pm 1.0$ & $4.8 \pm 0.7$ & $6.3 \pm 1.0$ & $4.7 \pm 0.9$ & $4.5 \pm 0.5$ & $4.8 \pm 0.5$ \\
\hline 2 & $5.2 \pm 0.5$ & $6.6 \pm 1.6$ & $7.7 \pm 1.0$ & $6.4 \pm 0.7$ & $5.3 \pm 0.5$ & $4.9 \pm 1.0$ & $4.3 \pm 0.6$ \\
\hline 3 & $4.9 \pm 0.9$ & $6.5 \pm 1.9$ & $8.7 \pm 1.4$ & $7.1 \pm 1.6$ & $7.3 \pm 1.1$ & $9.6 \pm 1.7$ & $6.0 \pm 1.4$ \\
\hline 6 & $8.4 \pm 0.4$ & $9.5 \pm 1.1$ & $9.3 \pm 0.5$ & $11.4 \pm 0.8$ & $9.0 \pm 0.4$ & $10.2 \pm 0.6$ & $9.3 \pm 0.3$ \\
\hline
\end{tabular}

Table 4. $\mathrm{FeNa}(\%)$ in puppies sustaining volume expansion (mean \pm S.E.)

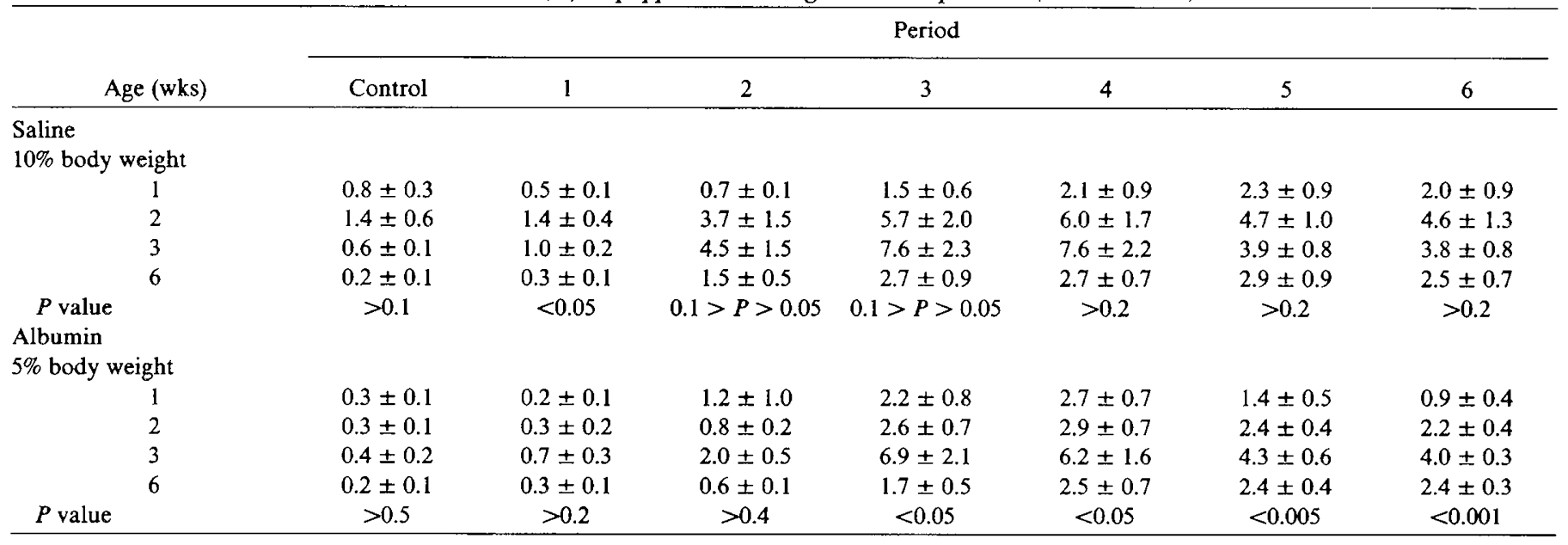

4) and the maximal difference between control and postexpansion values being significantly larger $(P<0.05)$ in the 3-wk-old puppies $(7.2 \pm 2.0 \%)$ than in the 1 -, 2 - or 6-wk-old animals $(2.3 \pm 0.8,2.6$ \pm 0.7 , and $2.3 \pm 0.8 \%$, respectively). Thus, the observation made under conditions of isotonic saline expansion, namely that the age-related difference in natriuresis was due in large part to differences in tubular reabsorption rather than in the filtered load of $\mathrm{Na}$ was also apparent in puppies sustaining isoncotic volume expansion.
In order to determine whether the quantitative relationship between the response to saline and that to albumin changed as a function of age, the data were subjected to two-way analysis of variance, and the statistical significance of interactions between the nature of expansion and age were determined (Tables 5-7). There were no significant interactions, indicating that the difference in response between saline and albumin expansion did not change with age. It should be noted however that, as in the oneway analysis of variance, significant differences between age 
Table 5. $U_{N a} V(m E q / m i n$ per $k g$ body weight $)$

\begin{tabular}{|c|c|c|c|c|c|c|c|}
\hline & \multicolumn{7}{|c|}{ Period } \\
\hline & Control & 1 & 2 & 3 & 4 & 5 & 6 \\
\hline $1 \mathrm{wk}$ & $2.5 \pm 0.5$ & $2.0 \pm 0.5$ & $6.4 \pm 3.8$ & $19.5 \pm 5.9$ & $13.1 \pm 2.9$ & $8.3 \pm 2.2$ & $6.4 \pm 2.0$ \\
\hline 2 wk & $3.3 \pm 1.2$ & $5.8 \pm 2.4$ & $17.9 \pm 5.9$ & $30.6 \pm 8.3$ & $25.8 \pm 4.7$ & $21.1 \pm 4.0$ & $15.9 \pm 3.1$ \\
\hline $3 \mathrm{wk}$ & $3.8 \pm 1.2$ & $10.9 \pm 3.4$ & $38.2 \pm 11.1$ & $70.7 \pm 12.7$ & $60.8 \pm 6.0$ & $45.9 \pm 7.4$ & $26.1 \pm 5.0$ \\
\hline $6 \mathrm{wk}$ & $2.7 \pm 1.0$ & $5.0 \pm 1.6$ & $12.4 \pm 3.8$ & $28.5 \pm 5.7$ & $36.8 \pm 7.7$ & $33.4 \pm 6.4$ & $31.5 \pm 5.4$ \\
\hline Saline & $4.1 \pm 1.0$ & $9.3 \pm 2.3$ & $24.7 \pm 8.0$ & $45.8 \pm 9.5$ & $36.3 \pm 6.2$ & $24.2 \pm 4.4$ & $19.9 \pm 4.2$ \\
\hline Albumin & $2.2 \pm 0.4$ & $3.2 \pm 0.8$ & $11.1 \pm 2.0$ & $30.2 \pm 4.9$ & $32.4 \pm 4.8$ & $29.7 \pm 5.0$ & $20.1 \pm 3.0$ \\
\hline$P^{1}$ & $>0.7$ & $<0.05$ & $<0.01$ & $<0.002$ & $<0.001$ & $<0.002$ & $<0.002$ \\
\hline$P^{2}$ & $>0.1$ & $<0.01$ & $<0.02$ & $>0.2$ & $>0.5$ & $>0.3$ & $>0.9$ \\
\hline$P^{3}$ & $>0.4$ & $>0.4$ & $>0.3$ & $>0.5$ & $>0.8$ & $>0.1$ & $>0.9$ \\
\hline
\end{tabular}

${ }^{1}$ Significance levels for differences among age groups independent of the solution used for expansion.

${ }^{2}$ Significance levels for differences between the response to saline and albumin infusion independent of age.

${ }^{3}$ Significance levels for differences resulting from the combined effects of age and solution used for expansion.

Table 6. Glomerular filtration rate $(\mathrm{ml} / \mathrm{min}$ per $\mathrm{kg}$ body weight)

\begin{tabular}{|c|c|c|c|c|c|c|c|}
\hline & \multicolumn{7}{|c|}{ Period } \\
\hline $1 \mathrm{wk}$ & $3.5 \pm 0.4$ & $3.9 \pm 0.6$ & $4.3 \pm 0.6$ & $5.6 \pm 0.8$ & $4.8 \pm 0.6$ & $3.4 \pm 0.5$ & $3.7 \pm 0.5$ \\
\hline $3 \mathrm{wk}$ & $5.5 \pm 0.7$ & $8.1 \pm 1.5$ & $8.6 \pm 0.8$ & $8.9 \pm 2.1$ & $7.1 \pm 0.7$ & $6.2 \pm 2.0$ & $5.5 \pm 1.0$ \\
\hline $6 \mathrm{wk}$ & $8.2 \pm 1.0$ & $9.7 \pm 1.0$ & $9.4 \pm 1.2$ & $10.6 \pm 1.3$ & $9.4 \pm 1.1$ & $9.2 \pm 0.6$ & $9.0 \pm 0.9$ \\
\hline Saline & $4.8 \pm 0.8$ & $6.9 \pm 1.0$ & $6.5 \pm 0.9$ & $7.5 \pm 1.4$ & $6.3 \pm 0.8$ & $5.0 \pm 0.7$ & $4.7 \pm 0.8$ \\
\hline$P^{2}$ & $>0.2$ & $>0.8$ & $>0.2$ & $>0.8$ & $>0.7$ & $<0.005$ & $0.1>P>0.05$ \\
\hline$P^{3}$ & $>0.2$ & $>0.2$ & $>0.5$ & $>0.4$ & $>0.7$ & $>0.7$ & $>0.8$ \\
\hline
\end{tabular}

${ }^{1}$ Significance levels for differences among age groups independent of the solution used for expansion.

${ }^{2}$ Significance levels for differences between the response to saline and albumin infusion independent of age.

${ }^{3}$ Significance levels for differences resulting from the combined effects of age and solution used for expansion.

Table 7. FeNa (\%)

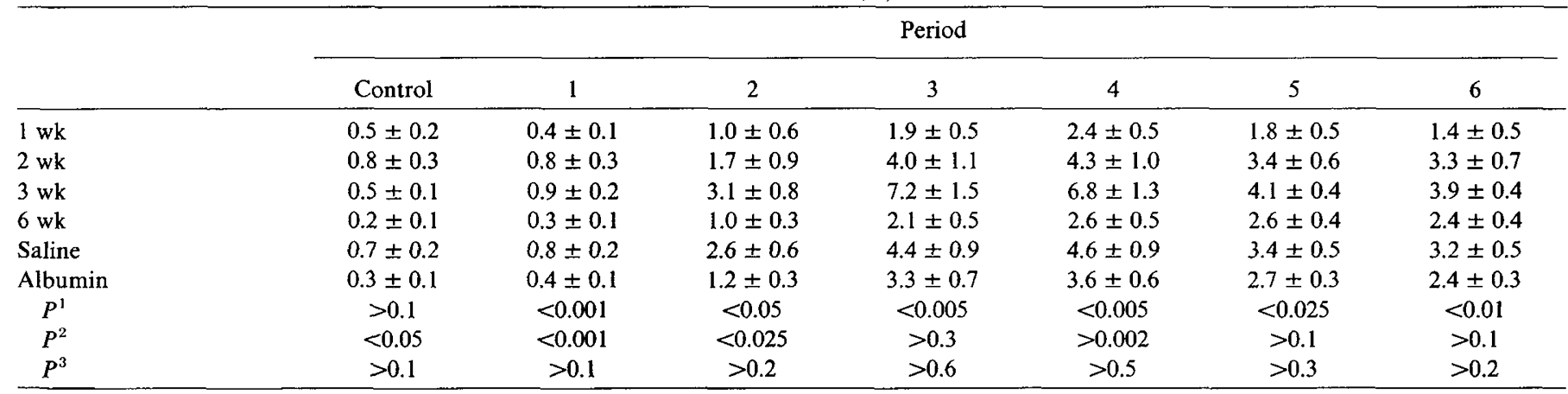

${ }^{1}$ Significance levels for differences among age groups independent of the solution used for expansion.

${ }^{2}$ Significance levels for differences between the response to saline and albumin infusion independent of age.

${ }^{3}$ Significance levels for differences resulting from the combined effects of age and solution used for expansion.

groups were demonstrable with either expansion fluid both during and after expansion. In addition, the two way analysis of variance demonstrated that the effect produced by the two expansion fluids differed only during the expansion procedure. The overall effect of these differences is illustrated in Figure 1, which depicts the cumulative sodium excretion, an index of the overall homeostatic response, during the study.

The analysis of variance demonstrated that the changes in GFR were independent of the nature of the expansion solution. GFR rose and then fell in all age groups whether the fluid administered was isotonic saline or isoncotic albumin; however, after the completion of expansion, the fall in GFR was less in the animals which received the albumin solution. The difference between the response to saline and that to albumin was not influenced by the age of the animal.
In contrast to the similar effect of the saline and albumin expansion on GFR, the two fluids had diverse effects on FeNa, this being significantly higher during saline expansion than during isoncotic albumin expansion. After the completion of expansion, $\mathrm{FeNa}$ tended to remain higher in the saline-treated puppies than in those receiving albumin, but the differences were not statistically significant. These effects on $\mathrm{FeNa}$ were observed in each age group and did not vary significantly with age.

\section{DISCUSSION}

Contrary to the expectation, the infusion of either isotonic saline or isoncotic albumin had similar effects on each age group studied, but as anticipated, a much greater proportion of the isoncotic albumin load was retained in the intravascular compartment. 


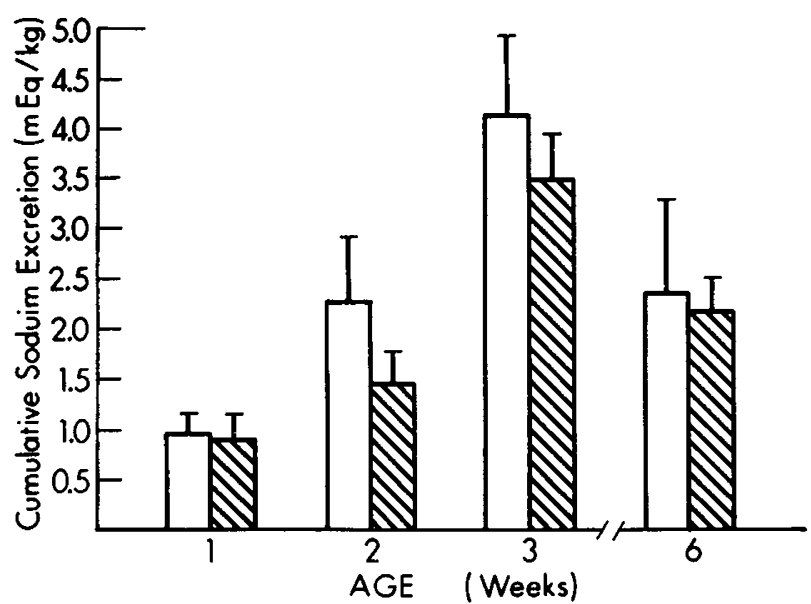

Fig. 1. Cumulative sodium excretion in developing animals sustaining volume expansion with either saline (open bars) or isoncotic albumin (hatched bars).

Saline loading therefore resulted in expansion of the intravascular and the interstitial compartments whereas albumin loading resulted predominantly in expansion of the intravascular volume. Because the proportion of the saline load that left the intravascular compartment was similar at all ages, the expansion of the interstitial volume must have been less in the newborn than in the 6-wkold animals due to the well known decline in the extracellular fluid relative to body weight that occurs during development. On the other hand, albumin loading provoked only minor expansion of the interstitial compartment at all ages, thus minimizing the effects of the extravascular expansion. Despite these differences in distribution, the age-related differences in natriuresis consequent to isoncotic albumin loading were similar to those observed after expansion with saline. We therefore conclude that the failure of the newborn to suppress sodium reabsorption to levels encountered in older animals cannot be attributed to relatively small degrees of expansion in the intravascular or interstitial compartment.

The factors controlling the distribution of fluid between the intravascular and interstitial compartments (i.e., transmural hydrostatic and oncotic pressures) and the rate at which equilibration occurs, (capillary permeability) were not examined in this study. Therefore, the mechanism responsible for a relatively large proportion of the saline load retained in the intravascular compartment of the newborn remains a matter of conjecture. Previous measurements of the rate of edema formation consequent to lowering of the interstitial pressure (20) or to trauma (15) indicated a higher rather than lower capillary permeability in the newborn as compared to older animals, suggesting that a slow rate of equilibration could not have accounted for our findings and that the pressure gradients across the capillary bed change as a function of age. Since the transmural oncotic pressure gradient would be expected to be low in the newborn due to both the low plasma protein concentration and the high capillary permeability, it seems reasonable to conclude that the hydrostatic pressure gradient across the capillary is also low at this particular stage of development. This would account for the observation that the proportion of fluid leaving the intravascular compartment is small relative to the ratio of intravascular to interstitial fluid volume.

The current studies confirm previous observations regarding the high rate of tubular reabsorption of $\mathrm{Na}^{+}$in the immature animal $(7,12,13)$ and extends them to the natriuresis observed following volume expansion with isoncotic albumin. At each age GFR rose during the expansion period proportionately to the baseline level; however, the natriuretic response was substantially less in 1- and 6-wk-old puppies than it was in the 3-wk-old animals, the difference being due primarily to the higher FeNa prevailing at this latter age. It might be noted that although the variability was large, significant differences in both $\mathrm{FeNa}$ and $\mathrm{U}_{\mathrm{Na}} \mathrm{V}$ were de- monstrable among age groups with either one- or two-way analysis of variance. On the other hand, the differences in the changes in GFR among age groups failed to reach statistically significant levels in any of the analyses. It therefore seems reasonable to conclude that our failure to demonstrate age-related differences in the increment in GFR was not due solely to the large variability, which was also encountered in the measurements of $\mathrm{FeNa}$ and $\mathrm{U}_{\mathrm{Na}} \mathrm{V}$. The current experiments also confirm our previous observations that developmental alterations in hematocrit are not responsible for the higher FeNa encountered around 3 wk of age (7). In addition, our results clearly demonstrate that the greater response observed at this stage of postnatal development cannot be explained by the degree of volume expansion, and has to be assigned to characteristics of renal tubular transport of sodium.

The mechanism responsible for the age-related differences in natriuretic response remains to be fully defined. Our previous work $(6,7)$ suggested that the high levels of renin and aldosterone might be pertinent because the natriuretic response to saline expansion was proportional to the decrease in the amount of circulating renin. Another possibility is that the changes in the response of the developing animal might be due to alterations in the amount of circulating natriuretic hormones (13).

Experiments performed by Osgood et al. $(18,19)$ have provided evidence that the expansion with Ringer's solution suppresses $\mathrm{FeNa}$ in the juxtamedullary nephrons, whereas expansion with hyperoncotic albumin fails to do so. In contrast, the FeNa of the superficial nephrons is affected by either procedure. In addition, these authors have demonstrated that after expansion with Ringer's solution the natriuretic response of the superficial nephrons is smaller than that of the nephrons located deep in the cortex $(18,19)$. The results of our previous studies in young animals sustaining saline expansion (7) suggested to us that the observations of Osgood et al. might be relevant to our understanding of the development of the natriuretic response to volume expansion. We found that the increase in FeNa rose initially with age and then fell. It seemed plausible to us that the increase in FeNa could be the result of the earlier maturation of the juxtamedullary nephrons as compared to those located in the more superficial cortex $(2,8,11,27)$. Subsequently, the response to volume expansion with saline might be expected to diminish as the superficial nephrons assume their functionally predominant role. If this were indeed the case, expansion with an albumin solution, which affects predominantly or exclusively the superficial nephrons, would be expected to elicit a progressive increase in $\mathrm{FeNa}$ with no subsequent decline being observed at a later stage of development. The fact that the changes in the responses to isoncotic albumin and isotonic saline closely parallel each other over the entire age span covered by these observations demonstrates that the difference in response is not dependent upon the presence of mature superficial nephrons; however, micropuncture studies and experiments on isolated perfused nephron segments will be necessary to quantify the contribution of specific nephron segments to the overall natriuresis observed with either saline or albumin loading.

The similarity of the age-related changes in natriuresis consequent to volume expansion with either saline or albumin suggests that a particular mechanism or nephron segment, which is sensitive to both types of expansion, is likely to be responsible for the similarity in the development of the renal response to these procedures. Sonnenberg (22-26) as well as Stein and his coworkers $(28,29)$ have suggested that the collecting duct plays a decisive role in regulating sodium excretion following volume expansion with either Ringer's or albumin containing solutions. Moreover, this segment of the nephron which has been shown to be influenced by prior exposure to aldosterone (21) appears to respond to a lesser extent to albumin loading than it does to expansion with Ringer's $(28,29)$. Our findings are consistent with these observations and indicate that the mechanism responsible for the difference in response to these solutions is already operative at birth, and they are compatible with the hypothesis that limited response of the neonatal animal to volume expansion is mediated by the renin-angiotensin-aldosterone system. 


\section{REFERENCES AND NOTES}

1. Aperia, A., Broberger, O., Thodenius, K., and Zetterstrom, R.: Renal response to an oral sodium load in newborn full-term infants. Acta Pediatr. Scand., 61: 670 (1972).

2. Aschinberg, L. C., Goldsmith, D. I., Olbing, O., Spitzer, A., Edelmann, C. M., Jr., and Blaufox, M. D.: Neonatal changes in renal blood flow distribution in puppies. Amer. J. Physiol., 228: 1453 (1975).

3. Cheek, D. B.: Extracellular volume: its structure and measurement and the influence of age and disease. J. Pediatr., 58: 103 (1961).

4. Darrow, D. C., Soule, H. C., and Buckman, T. E.: Blood volume in normal infants and children. J. Clin. Invest., $5: 243$ (1928).

5. Daugharty, T. M., Ueki, I. F., Nicholas, D. P., and Brenner, B. M.: Comparative renal effects of isoncotic and colloid free volume expansion in the rat. Amer. J. Physiol., 222: 225 (1972).

6. Drukker, A., Goldsmith, D. I., Spitzer, A., Edelmann, C. M., Jr., and Blaufox, M. D.: The renin-angiotensn system in newborn dogs. Prediatr. Res., 14: 304 (1980).

7. Goldsmith, D. I., Drukker, A., Blaufox, M. D., Edelmann, C. M., Jr., and Spitzer, A.: Hemodynamic and excretory responses of the neonatal kidney to acute volume expansion. Amer. J. Physiol., 237: F392 (1979).

8. Horster, M. and Valtin, H.: Postnatal development of renal function: micropuncture and clearance studies in the dog. J. Clin. Invest., 50: 779 (1971)

9. Friis-Hansen, B.: Body water compartments in children: changes during growth and related changes in body composition. Pediatrics, 28: 169 (1961).

10. Howards, S. S., Davis, B. B., Knox, F. G., Wright, F. S., and Berliner, R. W.: Depression of the fractional sodium reabsorption by the proximal tubule of the $\operatorname{dog}$ without sodium diuresis. J. Clin. Invest., 47: 1561 (1968).

11. John, E., Goldsmith, D. I., and Spitzer, A.: Quantitative changes in the canine glomerular vasculature during development: physiologic implications. Kidney International, 20: 223 (1981).

12. Kleinman, L. I.: Renal sodium reabsorption during saline loading and distal blockade in newborn dogs. Amer. J. Physiol., 228: 1403 (1975).

13. Kleinman, L. I. and Banks, R. O.: Natriuretic effect of oxytocin on salineexpanded neonatal dogs. Amer. J. Physiol., 239: F589 (1980).

14. Knox, F. G., Howards, S. S., Wright, F. S., Davis, B. B., and Berliner, R. W.: Effect of dilution and expansion of blood volume on proximal sodium reabsorption. Amer. J. Physiol., 215: 1041 (1968).

15. Little, R. A.: Effect of age on post-traumatic fluid loss. Brit. J. Exptl. Pathol., 53: $180,(1972)$.

16. McCance, R. A. and Widdowson, E. M.: The response of the newborn puppy to water, salt, and food. J. Physiol., 141: 81 (1958).

17. Morse, M., Cassells, D. E., and Schlutz, F. W.: Blood volumes of normal children. Amer. J. Physiol., 151: 448 (1947).

18. Osgood, R. W., Reineck, H. J., and Stein, J. H.: Further studies on segmental sodium transport in the rat kidney during expansion of the extracellular fluid volume. J. Clin. Invest., 62: 311 (1978).
19. Osgood, R. W., Reineck, H. J. and Stein, J. H.: Effect of hyperoncotic albumin on superficial and juxtamedullary nephron sodium transport. Amer. J. Physiol., 237: F34 (1979)

20. Rosenthal, S. M. and LaJohn, L. A.: Effect of age on transvascular fluid movement. Amer. J. Physiol., 228: 134 (1975)

21. Schwartz, G. J. and Burg, M. B.: Mineralocorticoid effects on cation transport by cortical collecting tubules. Am. J. Physiol., 240: F576 (1978).

22. Sisson, T. R. C., Lund, C. J., Whalen, L. E., and Telek, A.: The blood volume of infants: I. The full-term infant in the first year of life. J. Pediatr., 55: 163 (1959).

23. Snedecor, G. W. and Cochran, W. G - Statistical Methods: Sixth Edition; pp. 258-377. (The Iowa State University Press, Ames, Ia, 1967).

24. Sonnenberg, H.: Medullary collecting duct function in antidiuretic and in salt- or water-diuretic rats. Amer. J. Physiol., 226: 501 (1974).

25. Sonnenberg, H.: Secretion of salt and water into the medullary collecting duct of Ringer-infused rats. Amer. J. Physiol., 28: 565 (1975).

26. Sonnenberg, H.: Effect of adrenalectomy on medullary collecting duct function in rats before and during blood volume expansion. Pflugers Arch., 368: 55 (1977).

27. Spitzer, A. and Brandis, M.: Functional and morphological maturation of the superficial nephrons: relationship to total kidney function. J. Clin. Invest., 53: 279 (1974).

28. Stein, J. H., Osgood, R. W., Boonjarern, S., and Ferris, T. F.: A comparison of the segmental analysis of sodium reabsorption during Ringer's and hyperoncotic albumin infusion in the rat. J. Clin. Invest., 52: 2313 (1973).

29. Stein, J. H., Osgood, R. W., and Kunau, R. T., Jr.: Direct measurement of papillary collecting duct sodium transport in the rat. J. Clin. Invest., 58: 767 (1976).

30. Wallin, J. D., Blantz, R. C., Katz, M. A., Andreucci, V. E., Rector, F. C., Jr., and Seldin, D. W.: Effect of saline diuresis on intrarenal blood flow in the rat. Am. J. Physiol., 221: 1297 (1971).

31. Wallin, J. D., Rector, F. C., Jr., and Seldin, D. W.: Effect of volume expansion on intrarenal distribution of plasma flow in the dog. Amer. J. Physiol., 223: 125 (1972).

32. Walser, M., Davidson, D. G., and Orloff, J.: The renal clearance of alkali-stable inulin. J. Clin. Invest., 34: 1520 (1955).

33. The authors would like to thank Ms. Beth Zavilowitz for her technical aid in the performance of these studies and Ms. Veronica Mimnaugh for her secretarial assistance.

34. Requests for reprints should be addressed to: D. I. Goldsmith, M.D., Division of Pediatric Nephrology, Rose F. Kennedy Center, Room 721, 1410 Pelham Parkway South, Bronx, New York 10461.

35. Supported in part by grants no. 5RO1 HD 10559 and 5T32 AM 07110 from the National Institutes of Health and by the Kidney Foundation of New York.

36. Received for publication June 11, 1981.

37. Accepted for publication March 10, 1982 